\title{
Simulation of condensation in raw biogas containing $\mathrm{H}_{2} \mathrm{~S}$
}

\author{
Terje Bråthen ${ }^{1}$ Lars Erik Øi ${ }^{1}$ Jon Hovland ${ }^{2}$ \\ ${ }^{1}$ Department of and Process, Energy and Environmental Technology, University of South-Eastern Norway \\ ${ }^{2}$ SINTEF Tel-Tek, SINTEF Industry, Porsgrunn, Norway \\ lars.oidusn.no
}

\begin{abstract}
Condensation in raw biogas during compression is a problem because the $\mathrm{CO}_{2}$, water and $\mathrm{H}_{2} \mathrm{~S}$ in the liquid phase is very corrosive. Raw biogas typically contains 60 mol-\% methane, 40 mol- $\% \mathrm{CO}_{2}$, is saturated with water and may contain contaminants as $\mathrm{H}_{2} \mathrm{~S}$. In case of $\mathrm{H}_{2} \mathrm{~S}$, it is of interest whether it has influence on the dew point (condensation) temperature. The aim of this work is to calculate the dew point under different conditions using different equilibrium models. Phase envelopes showing the two-phase area are also calculated. There is traditionally only one constant binary parameter for each component pair in standard models like PengRobinson (PR) and Soave-Redlich-Kwong (SRK). In the process simulation tools Aspen HYSYS and Aspen Plus, the binary parameter for water $/ \mathrm{CO}_{2}$ and water $/ \mathrm{H}_{2} \mathrm{~S}$ can be made temperature dependent. For dry mixtures of methane and $\mathrm{CO}_{2}$ with up to 1 mol- $\% \mathrm{H}_{2} \mathrm{~S}$ (a high value for biogas), the different models gave similar results. When the $\mathrm{H}_{2} \mathrm{~S}$ increased from 0 to $1 \mathrm{~mol}-\%$, the dew point temperature increased with typically $1.0 \mathrm{~K}$. When water was included, the amount of calculated $\mathrm{H}_{2} \mathrm{~S}$ dissolved in water varied considerably with the model and on the selected binary parameter for water $/ \mathrm{H}_{2} \mathrm{~S}$. For biogas simulation, it is recommended to select a binary parameter (fitted to -0.036 at $25^{\circ} \mathrm{C}$ for PR) that fits the experimental data for $\mathrm{H}_{2} \mathrm{~S}$ solubility in water.
\end{abstract}

Keywords: $\mathrm{CO}_{2}$, methane, water, biogas, phase envelope, Aspen HYSYS, Aspen Plus

\section{Introduction}

Condensation in biogas containing water and $\mathrm{H}_{2} \mathrm{~S}$ during compression is a challenge because the $\mathrm{CO}_{2}$, water and $\mathrm{H}_{2} \mathrm{~S}$ in the liquid phase is very corrosive. Raw biogas typically contains 60 mol- $\%$ methane, 40 mol- $\%$ $\mathrm{CO}_{2}$, is saturated with water and may contain contaminants as $\mathrm{H}_{2} \mathrm{~S}$. Under compression up to $300 \mathrm{bar}$, it is a question whether condensation (mostly water) will occur. When the biogas contains $\mathrm{H}_{2} \mathrm{~S}$, it is of interest whether it has influence on the dew point temperature. It is also of interest how much $\mathrm{H}_{2} \mathrm{~S}$ will condense in the liquid phase.
This work is a continuation of the work from Øi and Hovland (2018) and Bråthen et al. (2019) which did not consider $\mathrm{H}_{2} \mathrm{~S}$.

Traditionally, gas mixture properties of methane, $\mathrm{CO}_{2}, \mathrm{H}_{2} \mathrm{~S}$ and water are calculated in a process simulation program with standard models like PR (Peng and Robinson, 1976) and SRK (Soave, 1972). There is traditionally only one constant binary parameter for each component pair. In the process simulation tools Aspen HYSYS and Aspen Plus, the binary parameter for water $/ \mathrm{CO}_{2}$ and water $/ \mathrm{H}_{2} \mathrm{~S}$ can be made temperature dependent. Other models are also available in Aspen HYSYS and Aspen Plus. Properties of mixtures of the biogas components have been studied extensively in natural gas processing where the methane concentration is very high. The same components have also been studied in the development of $\mathrm{CO}_{2}$ injection into different hydrocarbon reservoirs (Ziabakhsh-Ganji and Kooi, 2012). There have been found few articles about process simulation of biogas (Tan et al., 2017; Pellegrini et al., 2015; Ahmad et al., 2018), but these are not considering $\mathrm{H}_{2} \mathrm{~S}$.

When using fitted binary parameters ( $\mathrm{k}_{\mathrm{ij}}$ parameters) these models simulate the gas phase and the condensation point reasonably accurately (within a few degrees) at least below the critical point which is 46 bar for methane and 74 bar for $\mathrm{CO}_{2}$ (Øi and Hovland 2018; Bråthen et al., 2019).

Studies of models for vapour/liquid equilibrium in the methane/ $\mathrm{CO}_{2} /$ water-system have been performed by Jarne (2004) Austegard et al. (2006), Privat and Jaubert (2014), Al Ghafri et al. (2014), Legoix et al. (2017) and Bråthen et al. (2019). Only Privat and Jaubert (2014) included $\mathrm{H}_{2} \mathrm{~S}$ in the study. Austegard et al. (2006) concluded that a simple equation of state like SRK is satisfactory to describe the vapour phase, but more complex models are necessary to describe the liquid phase.

Several authors have studied models for the system $\mathrm{CO}_{2}$ /water (Spycher et al., 2003; Longhi, 2005; Aasen et al., 2017). Bråthen et al. (2019) concluded that PR and SRK with a standard $\mathrm{k}_{\mathrm{ij}}$ value were able to simulate this system satisfactory, at least for the vapour phase up to the critical point (40-70 bar).

References for $\mathrm{CH}_{4} / \mathrm{CO}_{2}$ /water including $\mathrm{H}_{2} \mathrm{~S}$ are Søreide and Whitson (1992) and $\mathrm{Li}$ et al. (2014). Søreide and Whitson calculated $\mathrm{k}_{\mathrm{ij}}$ values fitted to 
measured vapour phase compositions and different values fitted to liquid phase compositions.

There has been published work including $\mathrm{H}_{2} \mathrm{~S}$ using more advanced thermodynamic models in e.g. predictive PR (Privat et al., 2008), SAFT-VR (Perez et al., 2017). In this work, the emphasis is on the standard PR and SRK methods available in the process simulation programs Aspen HYSYS and Aspen Plus.

The aim of this work is to calculate the dew point or condensation of biogas containing $\mathrm{H}_{2} \mathrm{~S}$ under different conditions with varied temperature, pressure and gas composition and using different equilibrium models.

\section{Simulation Programs and Models}

$\varnothing_{\mathrm{i}}$ and Hovland (2018) and Bråthen et al. (2019) simulated dry biogas $\left(\mathrm{CH}_{4}\right.$ and $\left.\mathrm{CO}_{2}\right)$ and mixtures also containing water using the process simulation programs Aspen HYSYS and Aspen Plus. The equilibrium models SRK (Soave, 1972), PR (Peng and Robinson, 1976) and also other models were used.

The reason why the simple models PR and SRK are selected, is that the models and fitted binary parameters are usually available in different process simulation programs. Other commercial process simulation programs are ProMax, ChemCad, and ProTreat.

In Aspen HYSYS and Aspen Plus the PR and SRK models have only one adjustable parameter for each binary component pair, but for some components, and especially water $/ \mathrm{CO}_{2}$ and water $/ \mathrm{H}_{2} \mathrm{~S}$, this parameter may be temperature dependent.

Equations for the SRK equation of state are shown in (1) to (8) from Aspen HYSYS Version 10. Aspen HYSYS and Aspen Plus Version 10 were used in the simulations. More details are discussed in Bråthen et al. (2019).

$$
\begin{aligned}
& p=\frac{R T}{v-b}-\frac{a}{v(v+b)} \\
& b=\sum_{i=1}^{N} x_{i} b_{i} \\
& b_{i}=\frac{0,08664 R T_{C}}{p_{c}} \\
& a=\sum_{i=1}^{N} \sum_{j=1}^{N} x_{i} x_{j}\left(a_{i} a_{j}\right)^{0,5}\left(1-k_{i j}\right) \\
& a_{i}=a_{c i} \alpha_{i} \\
& a_{c i}=\frac{0,42748 R^{2} T_{c}^{2}}{p_{c}} \\
& \alpha_{i}=\left[1+m_{i}\left(1-T_{r}^{1 / 2}\right)\right]^{2} \\
& m_{i}=0,48+1,574 \omega_{i}-0,176 \omega_{i}^{2}
\end{aligned}
$$

$\mathrm{P}, \mathrm{T}, \mathrm{V}$ and $\mathrm{R}$ are the pressure, temperature, molar volume and the universal gas constant. $T_{c}$ is the critical temperature, $\omega$ is the acentric factor and $T_{r}$ is the reduced temperature (the ratio between $T$ and $T_{c}$ ). The binary interaction parameter $\mathrm{k}_{\mathrm{ij}}\left(=\mathrm{k}_{\mathrm{ji}}\right)$ is a constant for a binary component pair and $\mathrm{x}_{\mathrm{i}}$ is the mole fraction for component $\mathrm{i}$. In the PR equation, equation $1,3,6$ and 8 are replaced by equation $9,10,11$ and 12 .

$$
\begin{aligned}
& p=\frac{R T}{v-b}-\frac{a}{v(v+b)+b(v-b)} \\
& b_{i}=\frac{0,077796 R T_{C}}{p_{c}} \\
& a_{c i}=\frac{0,457235 R^{2} T_{c}^{2}}{p_{c}} \\
& m_{i}=0,37464+1,54226 \omega_{i}-0,26992 \omega_{i}{ }^{2}
\end{aligned}
$$

The binary parameter $\mathrm{k}_{\mathrm{ij}}$ is normally a constant for each binary pair. When utilizing the default $\mathrm{k}_{\mathrm{ij}}$ values in Aspen HYSYS and Aspen Plus, the $\mathrm{k}_{\mathrm{ij}}$ values are constant for all component pairs except for water $/ \mathrm{CO}_{2}$ and water $/ \mathrm{H}_{2} \mathrm{~S}$ where it is a temperature dependent function. Different optimized values for the $\mathrm{k}_{\mathrm{ij}}$ values can be found because the parameters may be optimized for different conditions, e.g., for accurate prediction of either the gas phase or the condensate phase. For the calculation of dew points, it is reasonable to use binary interaction coefficients optimized for the gas phase (Bråthen et al., 2019).

The PR and SRK versions used in Aspen Plus are equal to the Aspen HYSYS versions shown in (1) to (12), except that some of the numerical values are slightly different. Especially the coefficients in the $\mathrm{m}_{\mathrm{i}}$ expressions (8) and (12) are slightly different.

The parameters in (1) to (12) may be slightly different in different process simulation programs. The alfa $\left(\alpha_{\mathrm{i}}\right)$ parameter in equation (7) can be calculated differently. In the PR-Twu and SRK-Twu models the $\alpha_{i}$ parameter is calculated in a different way (Twu et al., 1991).

Some references to suggest a $\mathrm{k}_{\mathrm{ij}}$ value for water/CO close to 0.19 are Ziabakshsh-Ganji and Kooi (2012), Li et al. (2014) and Bråthen et al. (2019). Some recommends different $\mathrm{k}_{\mathrm{ij}}$ values dependent on emphasis on the vapour or liquid phase (Austegard et al., 2006). Some values for water $/ \mathrm{H}_{2} \mathrm{~S}$ from literature are 0.17 and -0.02 optimized for the liquid and vapour phase, respectively (Søreide and Whitson, 1992). A value of 0.105 has been fitted to the binary mixture of water and $\mathrm{H}_{2} \mathrm{~S}$ (Li et al., 2014; Ziabakshsh-Ganji and Kooi, 2012). 


\section{Process Description and Simulation Specifications}

\subsection{Process description of raw biogas compression}

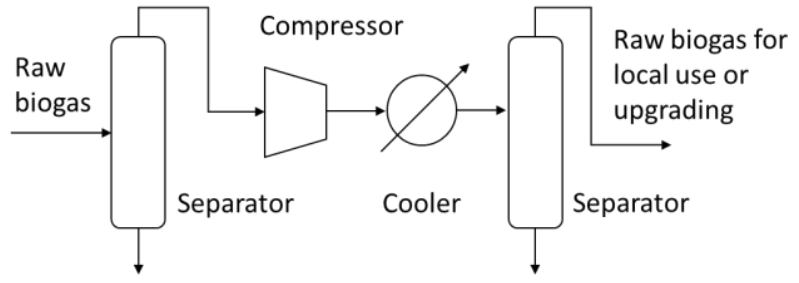

Figure 1. A traditional raw biogas compression process

The principle for a traditional raw biogas compression process is shown in Figure 1.

The actual process is discussed in more detail in Hovland (2017), Øi and Hovland (2018) and Bråthen et al. (2019). Hovland (2017) has suggested to compress the gas to a high pressure, typically above 100 bar, and transport it to a facility for upgrading to biomethane (almost pure methane).

As mentioned in Øi and Hovland (2018) and Bråthen et al. (2019), condensation during compression is regarded to be a problem, and should be avoided.

\subsection{Simulation specifications}

In earlier work, process simulations have been performed for different conditions relevant for biogas production as in Øi and Hovland (2018) and Bråthen et al. (2019). The models PR, SRK, TST, PR-Twu and SRK-Twu were used. For all the conditions, calculations with the default parameters (especially the $\mathrm{k}_{\mathrm{ij}}$ for water $/ \mathrm{CO}_{2}$ ) were used. Simulations with other $\mathrm{k}_{\mathrm{ij}}$ values have also been performed. Phase envelopes showing the dew and bubble point curve for a temperature and pressure range have been calculated. In the dry gas cases, the HYSYS 2-phase option was selected for phase envelope calculations. In the cases including water and $\mathrm{H}_{2} \mathrm{~S}$, the ComThermo 3-phase option was selected.

As a verification, calculations with Aspen Plus and the Stryjek-Vera (1986) model were performed. In Aspen Plus the Peng-Robinson and RKSoave models were selected. The B and D cases are referring to $\varnothing_{\mathrm{i}}$ and Hovland (2018) and simulated in Bråthen et al. (2019).

In earlier simulations (Case B) dry biogas with 40 mol- $\%$ methane and 60 mol- $\% \mathrm{CO}_{2}$ starts at $37{ }^{\circ} \mathrm{C}$ and $1 \mathrm{bar}$, is cooled to $10{ }^{\circ} \mathrm{C}$ and is compressed to $64 \mathrm{bar}$. In this work, 1 mol- $\% \mathrm{H}_{2} \mathrm{~S}$ is added, and the mol-\% methane is reduced to 39 .

In earlier simulations (Case D), $59.9 \mathrm{kmol} / \mathrm{h}$ methane, $40 \mathrm{kmol} / \mathrm{h} \mathrm{CO}_{2}$ and $0.1 \mathrm{kmol} / \mathrm{h}$ water is mixed at $37^{\circ} \mathrm{C}$ and $1 \mathrm{bar}$, cooled to $10^{\circ} \mathrm{C}$, and then compressed to 64 bar. In this work, $1 \mathrm{~mol}-\% \mathrm{H}_{2} \mathrm{~S}$ is added, and the mol-\% methane is reduced to 58.9 .

\section{Process Simulation, Results and Discussion}

\subsection{Simulation of dry methane/ $\mathrm{CO}_{2}$ mixture including $\mathrm{H}_{2} \mathrm{~S}$ (Case $\mathrm{B}$ )}

An Aspen HYSYS flow-sheet model of the process for the base case simulation is presented in Figure 2.

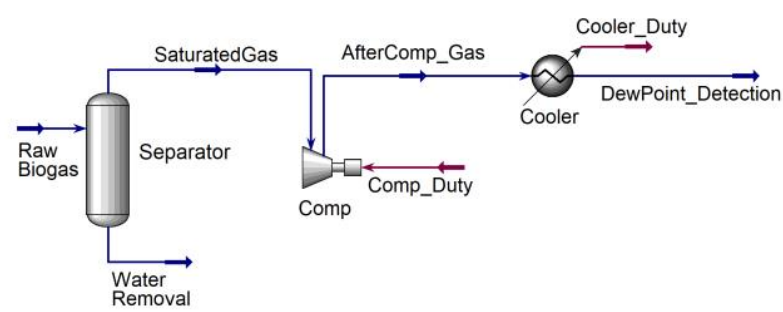

Figure 2. Aspen HYSYS flow-sheet for compression and cooling

In earlier calculations without $\mathrm{H}_{2} \mathrm{~S}$, Case $\mathrm{B}$ was of interest because a $40 \%$ methane and $60 \% \mathrm{CO}_{2}$ has a dew point close to $0{ }^{\circ} \mathrm{C}$. Earlier evaluations from $\varnothing \mathrm{i}$ and Hovland (2018) and Bråthen et al. (2019) have shown that below 60 mol- $\% \mathrm{CO}_{2}$, no condensation should appear if the temperature is kept above $-3{ }^{\circ} \mathrm{C}$.

Table 1. Dew point at 64 bar, cricondenterm and cricondenbar for a mixture of 39 mol- $\%$ methane, 60 mol$\% \mathrm{CO}_{2}$ and 1 mol- $\% \mathrm{H}_{2} \mathrm{~S}$ (Case B)

\begin{tabular}{|l|c|c|c|}
\hline Model & $\mathbf{T}_{\text {DEW }}$ & $\mathbf{T}_{\text {CRIC }}\left({ }^{\mathbf{0}} \mathbf{C}\right)$ & P $_{\text {CRIC }}$ (bar) \\
\hline PR Hysys & -4.4 & -0.5 & 89.5 \\
\hline SRK Hysys & -4.3 & -0.2 & 88.4 \\
\hline TST Hysys & $-2,3$ & -1.3 & 82.6 \\
\hline PR-Twu Hysys & $-5,3$ & -1.5 & 90.0 \\
\hline SRK-Twu Hysys & $-4,8$ & $-0,7$ & 90.5 \\
\hline PR Aspen Plus & -4.3 & -0.7 & 88.1 \\
\hline SRK Aspen Plus & -1.8 & 2.1 & 82.8 \\
\hline
\end{tabular}

The results in Table 1 are similar to the results from $\varnothing \mathrm{i}$ and Hovland (2018) and Brăthen et al. (2019). The results in Aspen HYSYS and Aspen Plus are not identical due to slightly different model parameters. The dew points are typically $1 \mathrm{~K}$ and for all the cases less than $3 \mathrm{~K}$ higher than the calculations for mixtures without $\mathrm{H}_{2} \mathrm{~S}$. These deviations are slightly less than the deviation in calculated dew point between different models used. 
Also when $\mathrm{H}_{2} \mathrm{~S}$ is included, the calculated cricondenterms with different models have a maximum deviation of less than $2 \mathrm{~K}$. It is concluded that the results can be expected to be fairly accurate for all the models evaluated. Even with 1 mol- $\% \mathrm{H}_{2} \mathrm{~S}$, no condensation will appear above $0{ }^{\circ} \mathrm{C}$ in a dry biogas with more than 40 mole- $\% \mathrm{CH}_{4}$. This was also the conclusion without $\mathrm{H}_{2} \mathrm{~S}$ from Hovland (2017), Øi and Hovland (2018) and Bråthen et al. (2019).

The phase envelope from Aspen HYSYS is shown in Figure 3. The dew point curve is to the right. The point with the highest temperature is the cricondenterm. The point with the highest pressure is the cricondenbar. In the critical point for the mixture, the compositions in both phases are equal.

The phase envelope in Figure 3 is very close to the phase envelope in Bråthen et al. (2019) which was calculated without $\mathrm{H}_{2} \mathrm{~S}$. This is the same comparison as the comparison of Table 1 which was also compared with simulations without $\mathrm{H}_{2} \mathrm{~S}$. Even in the region close to the critical point and at the maximum pressure, the deviation in temperature seems to be less than $2 \mathrm{~K}$.

These simulations indicate that the calculated dew points and phase envelopes for dry biogas including up to $1 \mathrm{~mol}-\% \mathrm{H}_{2} \mathrm{~S}$ are reasonably accurate for all the models tested.

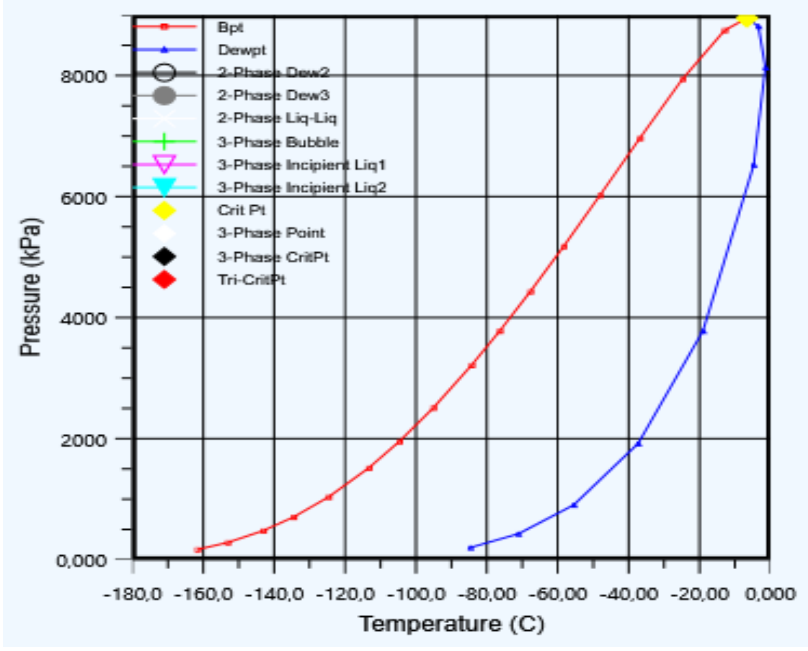

Figure 3. Phase envelope, Peng-Robinson, $\mathrm{CH}_{4}=0.39$, $\mathrm{CO}_{2}=0.6, \mathrm{H}_{2} \mathrm{~S}=0.01$. PR with default $\mathrm{k}_{\mathrm{ij}}$ values

\subsection{Simulation of compression of a raw biogas including water and $\mathrm{H}_{2} \mathrm{~S}$, Case $\mathrm{D}$}

The process (Case D) was simulated with water and $\mathrm{H}_{2} \mathrm{~S}$ included. The simulations are similar to the simulations in Bråthen et al. (2019) and in this work 1 mol-\% $\mathrm{H}_{2} \mathrm{~S}$ is added and the mole fraction of methane is reduced correspondingly. The results are shown in Table 2 .
Table 2. Dew point at 64 bar, cricondenterm and pressure at cricondenterm for a mixture of $58.9 \mathrm{~mol} \%$ $\mathrm{CH}_{4}, 40 \mathrm{~mol} \% \mathrm{CO}_{2}, 1 \mathrm{~mol} \% \mathrm{H}_{2} \mathrm{~S}, 0.1 \mathrm{~mol} \%$ water, CaseD

\begin{tabular}{|l|c|c|c|c|}
\hline Model & $\begin{array}{c}\mathbf{T}_{\text {DEW }} \\
\left({ }^{\circ} \mathbf{C}\right)\end{array}$ & $\begin{array}{c}\mathbf{T}_{\text {CRIC }} \\
\left({ }^{\circ} \mathbf{C}\right)\end{array}$ & $\begin{array}{c}\text { P }_{\text {CRIC }} \\
(\mathbf{b a r})\end{array}$ & $\mathbf{X}_{\text {H2S }}$ \\
\hline PR & 26.3 & -21.1 & 83.9 & 0.00062 \\
\hline SRK & 26.7 & -20.7 & 83.1 & 0.00058 \\
\hline PR $\left(k_{\mathrm{ij}}=0.105\right)$ & 26.4 & -21.1 & 83.9 & 0.000067 \\
\hline $\begin{array}{l}\text { PR }\left(\mathrm{k}_{\mathrm{ij}}=0.105\right) \\
\mathrm{k}_{\text {H2O/CO2 }=0.19}\end{array}$ & 29.5 & -21.1 & 83.9 & 0.000063 \\
\hline PRSV & 27.0 & -22.0 & 83.5 & 0.000091 \\
\hline TST+k $\mathrm{k}_{\mathrm{ij}}$ & 28.6 & -18.1 & 80.6 & 0.00062 \\
\hline PRTwu+k $\mathrm{k}_{\mathrm{ij}}$ & 28.4 & -22.1 & 83.6 & 0.00061 \\
\hline SRKTwu+k $\mathrm{k}_{\mathrm{ij}}$ & 28.6 & -21.5 & 84.2 & 0.00058 \\
\hline
\end{tabular}

In the work of Bråthen et al. (2019) other models were also used. The deviation between the models were small. The dew point temperatures in Table 2 were also calculated in Aspen Plus (Bråthen et al., 2019) in simulations without $\mathrm{H}_{2} \mathrm{~S}$ with other models like PR and SRK. The results were very close to the results using Aspen HYSYS. When using PR and SRK in Aspen Plus the results were identical in the two programs. There were deviations of up to $7 \mathrm{~K}$ between the dew point temperature dependent on $\mathrm{k}_{\mathrm{ij}}$ values.

The calculated cricondenterm values in Table 2 are very much lower than the values in Bråthen et al. (2019). This is probably because the values in this work were calculated without taking water into account. To evaluate the actual cricondenterm values, it is recommended to analyse the phase envelope in Figure 4 with the similar phase envelope in Bråthen et al. (2019). The dew point curves to the right in the figures are similar, and that is most relevant in this evaluation.

\subsection{Fitting of binary parameter for water/ $\mathrm{H}_{2} \mathrm{~S}$ based on literature data.}

In (Bråthen et al., 2019) the binary parameter $\left(\mathrm{k}_{\mathrm{ij}}\right)$ for water/ $/ \mathrm{CO}_{2}$ was varied to give a good fit to experimental dew point data for typical biogas compositions. For mixtures with a methane $/ \mathrm{CO}_{2}$ mole fraction ratio of $50 / 50$ and 70/30, an average value of 0.19 was calculated. This was recommended (Bråthen et al., 2019) to use for calculating dew points in biogas mixtures.

When adding up to $1 \mathrm{~mol}-\% \mathrm{H}_{2} \mathrm{~S}$ to a biogas mixture, the results in this work indicate that the dew point temperature is influenced to a low degree by varying the binary parameters $\left(\mathrm{k}_{\mathrm{ij}}\right.$ for water $\left./ \mathrm{H}_{2} \mathrm{~S}\right)$. The solubility of $\mathrm{H}_{2} \mathrm{~S}$ in water is however considerably influenced by the $\mathrm{k}_{\mathrm{ij}}$ for water $/ \mathrm{H}_{2} \mathrm{~S}$. 
In Table 2, the models giving similar $\mathrm{H}_{2} \mathrm{~S}$ solubility, gave a ratio of the partial pressure of $\mathrm{H}_{2} \mathrm{~S}(=0.64$ bar) and mole fraction $\mathrm{H}_{2} \mathrm{~S}$ between 1030 and 1100 bar. This can be seen as a Henry's constant, but at the pressure of 64 bar, the gas is not ideal, so as a Henry's constant, it is inaccurate. In Chapoy et al. (2005) similar ratios at $25^{\circ} \mathrm{C}$ can be calculated to values between 540 and 550 bar (approximately the $\mathrm{H}_{2} \mathrm{~S}$ Henry's constant) at total pressure between 5 and 7 bar in a water $/ \mathrm{H}_{2} \mathrm{~S}$ system. The Henrys constant at $25^{\circ} \mathrm{C}$ from NIST (2020) is 560 $\operatorname{bar}(0.10 \mathrm{~mol} /(\mathrm{kg} \cdot \mathrm{bar}))$.

To compare calculated Henry's constants with literature data, simulations with $1 \mathrm{~mol}-\% \mathrm{H}_{2} \mathrm{~S}$ and 99 mol- $\%$ water were performed. At $25^{\circ} \mathrm{C}$, the ratio was calculated to 670 bar with $\mathrm{k}_{\mathrm{ij}}=-0.034$ (default) and to 6300 bar with $\mathrm{k}_{\mathrm{ij}}=0.106$. This indicates that the default $\mathrm{k}_{\mathrm{ij}}$ give a Henry's constant close to literature data at a low pressure. Using a $\mathrm{k}_{\mathrm{ij}}$ value of 0.106 which is cited in some literature sources (Chapoy et al., 2005; Li et al., 2014) will give a wrong $\mathrm{H}_{2} \mathrm{~S}$ solubility by an order of magnitude.

The $\mathrm{k}_{\mathrm{ij}}$ for the water $/ \mathrm{H}_{2} \mathrm{~S}$ binary was adjusted to fit the Henry's constant (547 bar) at $25^{\circ} \mathrm{C}$ and the result was -0.036 . When using the PR and SRK models in Aspen HYSYS and Aspen Plus, the default temperature dependent $\mathrm{k}_{\mathrm{ij}}$ values give so reasonable results that it is not recommended to change the default $\mathrm{k}_{\mathrm{ij}}$ values.

\subsection{Phase envelope calculations}

The phase envelope for $\mathrm{PR}, \mathrm{k}_{\mathrm{ij}}=0.19$ for water/ $\mathrm{CO}_{2}$ and default $\mathrm{k}_{\mathrm{ij}}$ for water $/ \mathrm{H}_{2} \mathrm{~S}$, is shown in Figure 4.

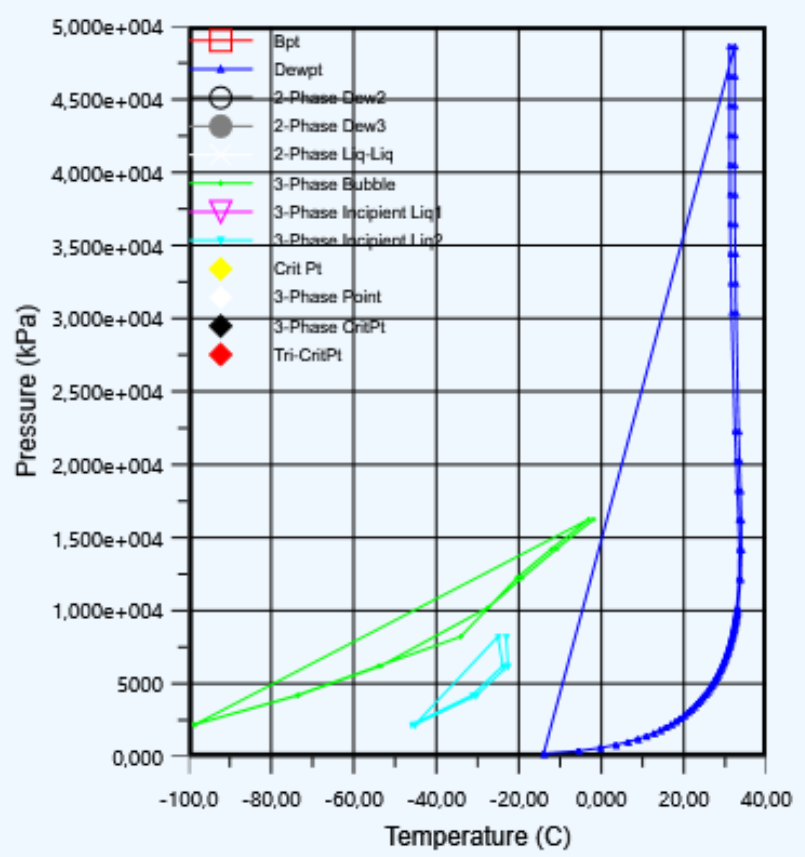

Figure 4. Phase envelope for PR model, $58,9 \mathrm{~mol} \%$ $\mathrm{CH}_{4}, 40 \mathrm{~mol} \% \mathrm{CO}_{2}, 1 \mathrm{~mol} \% \mathrm{H}_{2} \mathrm{~S}, 0.1 \mathrm{~mol} \%$ water: $\mathrm{k}_{\mathrm{ij}}$ $=0.19$ for water $/ \mathrm{CO}_{2}, \mathrm{k}_{\mathrm{ij}}=$ default for water $/ \mathrm{H}_{2} \mathrm{~S}$
The phase envelope in Figure $\mathbf{4}$ can be compared to a similar phase envelope from Bråthen et al. (2019) without $\mathrm{H}_{2} \mathrm{~S}$ included. The dew point line to the right in the figure deviate with less than about $2 \mathrm{~K}$ for the whole pressure range, compared to the figure without $\mathrm{H}_{2} \mathrm{~S}$ from 2019. This gives the conclusion that the inclusion of $\mathrm{H}_{2} \mathrm{~S}$ only slightly influence the dew point temperature calculations. Figure 4 shows however that there are some additional curves to the left in the figure. These are however at temperatures below $0^{\circ} \mathrm{C}$. In a raw biogas mixture, temperatures below $0{ }^{\circ} \mathrm{C}$ would give the risk of ice formation and hydrate formation. The temperature range below $0{ }^{\circ} \mathrm{C}$ is not evaluated in this work.

In general, it is expected that the uncertainty in dew point calculations increases when the pressure increases and the mixture is close to the critical point which is about 70 bar (Øi and Hovland, 2018; Bråthen et al., 2019). The range with an uncertainty less than $4 \mathrm{~K}$ in calculated dew point with PR or SRK with one constant $\mathrm{k}_{\mathrm{ij}}$ value (0.19) is for the range of temperatures $0-40^{\circ} \mathrm{C}$, pressures up to 70 bar and $\mathrm{CH}_{4}$ concentration above 30 mol-\%. This uncertainty is not significantly increased by a $\mathrm{H}_{2} \mathrm{~S}$ content up to $1 \mathrm{~mol}-\%$.

\section{Conclusion}

Specified mixtures of raw biogas with and without water have been simulated at different temperatures and pressures. The effect of adding up to $1 \mathrm{~mol}-\% \mathrm{H}_{2} \mathrm{~S}$ to the mixtures have been evaluated. Dew points have been calculated with different models and with different binary parameters. For some conditions, phase envelopes have been calculated and different models have been compared.

For mixtures of methane and $\mathrm{CO}_{2}$ with up to 1 mol$\% \mathrm{H}_{2} \mathrm{~S}$ (a high value for biogas), the different models gave similar results. Under normal ambient temperatures (above $0{ }^{\circ} \mathrm{C}$ ), a mixture with more than 40 mol- $\%$ methane will not give any condensation. When the $\mathrm{H}_{2} \mathrm{~S}$ increased from 0 to $1 \mathrm{~mol}-\%$, the dew point temperature increased with typically $1.0 \mathrm{~K}$. A phase envelope for biogas with $1 \mathrm{~mol}-\% \mathrm{H}_{2} \mathrm{~S}$ is only slightly different from an earlier calculated phase envelope for biogas without $\mathrm{H}_{2} \mathrm{~S}$.

When raw biogas is cooled or compressed, water will condense first. Some $\mathrm{H}_{2} \mathrm{~S}$ will dissolve in the water, and the amount of calculated $\mathrm{H}_{2} \mathrm{~S}$ dissolved in water varied significantly with the model and on the selected binary parameter for water $/ \mathrm{H}_{2} \mathrm{~S}$. Using the Peng-Robinson model with binary coefficients fitted to $\mathrm{H}_{2} \mathrm{~S}$ solubility either in the vapor or the liquid phase, gave results for the $\mathrm{H}_{2} \mathrm{~S}$ solubility in water with a factor of 10 in difference. For biogas simulation, it is recommended to select a binary parameter (fitted to -0.036 at $25{ }^{\circ} \mathrm{C}$ for PR) that fits experimental data for $\mathrm{H}_{2} \mathrm{~S}$ solubility in water. 


\section{References}

A. Aasen, M. Hammer, G. Skaugen, J. P. Jakobsen and $\varnothing$. Wilhelmsen. Thermodynamic models to accurately describe the PVTxy-behaviour of water/carbon dioxide mixtures, Fluid Phase Equilibria, 442:125-139, 2017.

N. E. Ahmad, M. Mel and N. Sinaga. Design of Liquefaction Process of Biogas using Aspen HYSYS Simulation. Journal of Advanced Research in Biofuel and Bioenergy, 2:10-15, 2018

S. Z. S. Al Ghafri, E. Forte, G. C. Maitland, J.J. RodriguezHenriquez and J. P. M. Trusler. Experimental and Modeling Study of the Phase Behaviour of (Methane + $\mathrm{CO} 2$ + Water) Mixtures. Journal of Physical Chemistry, 118:14462-14478, 2014.

A. Austegard, E. Solbraa, G. de Koeijer and M. J. Mølnvik. Thermodynamic models for calculating mutual solubilities in $\mathrm{H}_{2} \mathrm{O}-\mathrm{CO}_{2}-\mathrm{CH}_{4}$ mixtures. Trans IChemE, Part A, Chem. Eng. Res. Des., 84(A9):781-7946, 2006.

T. Bråthen, L. E. Øi and J. Hovland. Simulation of Dew Points in Raw Biogas Using PR and SRK Equations of State. In Linköping Electronic Conference Proceedings SIMS 60, pages 31-36, 2018. doi: 10.3384/ecp20170112

A. Chapoy, A. H. Mohammadi, B. Tohidi, A. Valtz and D. Richon. Experimental Measurements and Phase Behavior Modeling of Hydrogen Sulfide-Water Binary System. Ind. Eng. Chem. Res., 44:7567-7574, 2005.

J. Hovland. Compression of raw biogas - A feasibility study. Tel-Tek report 2217020-1, 2017. Available on https://www.biogas2020.se/wpcontent/uploads/2017/06/22170201compressionrawbiogas.pdf

C. Jarne, S. T. Blanco, M. A. Gallardo, E. Rauzi, S. Otin and I. Valesco. Dew Points of Ternary Methane (or Ethane) + Carbon Dioxide + Water Mixtures: Measurements and Correlation. Energy \& Fuels, 18:396-404, 2004.

L. N. Legoix, L. Ruffine, J. P. Donval and M. Haeckel. Phase Equilibria of the CH4-CO2 Binary and the $\mathrm{CH} 4-\mathrm{CO}_{2}-\mathrm{H}_{2} \mathrm{O}$ Ternary Mixtures in the Presence of a CO2-Rich Liquid Phase. Energies, 10(2034):1-11, 2017. Doi:10.3390/en10122034.

J. Li, L. Wei and X. Li. Modeling of CO2-CH4-H2S-brine based on cubic EOS and fugacity-activity approach and their comparisons. Energy Procedia, 63:3598-3607, 2014.

J. Longhi. Phase equilibria in the system $\mathrm{CO} 2-\mathrm{H} 2 \mathrm{O} \mathrm{I}$ : New equilibrium relations at low temperatures. Geochimica et Cosmochimica Acta, 69(3): 529-539, 2005.

NIST webbook (Link downloaded 27.6.2020) https://webbook.nist.gov/cgi/cbook.cgi?ID=C7783064\&Mas $\mathrm{k}=10 \#$ Solubility NIST

D. Peng and D. B. Robinson. A New Two-Constant Equation of State. Industrial \& Engineering Chemistry Fundamentals, 15(1):59-646, 1976.

L. Pellegrini. Biogas to liquefied biomethane via cryogenic upgrading technologies. Renewable Energy, 124:75-83, 2018.

G. Perez, C. Coquelet, P. Paricaud and A. Chapoy. Comparative study of vapour-liquid equilibrium and density modelling of mixtures related to carbon capture and storage with the SRK, PR, PC-SAFT and SAFT-VR Mie equations of state for industrial uses. Fluid Phase Equilibria, 77:440, 2017.

R. Privat, F. Mutelet and J. Jaubert. Addition of the Hydrogen Sulfide Group to the PPR78 Model (Predictive 1978, Peng-Robinson Equation of State with Temperature Dependent $\mathrm{k}_{\mathrm{ij}}$ Calculated through a Group Contribution Method). Industrial \& Engineering Chemistry Research, 47:10041-10052, 2008.

R. Privat and J. N. Jaubert, Predicting the Phase Equilibria of Carbon Dioxide Containing Mixtures Involved in CCS
Processes Using the PPR78 Model. InTech, 2014. Available on http://dx.doi.org/10.5772/57058.

G. Soave. Equilibrium constants from a modified Redlich Kwong equation of state. Chemical Engineering Science, 27:1197-1203, 1972.

N. Spycher, K. Pruess and J. Ennis-King. CO2-H2O mixtures in the geological sequestration of $\mathrm{CO} 2$. I. Assessment and calculation of mutual solubilities from 12 to $100{ }^{\circ} \mathrm{C}$ and up to 600 bar. Geochimica et Cosmochimica Acta, 67 (16):3015-3031, 2003.

R. Stryjek and J. H. Vera. PRSV - An Improved PengRobinson Equation of State with New Mixing Rules for Strongly Nonideal Mixtures. The Canadian Journal of Chemical Engineering, 64:334-340, 1986.

I. Søreide and C. H. Whitson. Peng-Robinson predictions for hydrocarbons, $\mathrm{CO} 2, \mathrm{~N} 2$, and $\mathrm{H} 2 \mathrm{~S}$ with pure water and $\mathrm{NaCl}$ brine. Fluid Phase Equilibria, 77:217-240, 1992.

Y. Tan, W. Nookuea, H. Li, E. Thorin and J. Yan. Cryogenic technology for biogas upgrading combined with carbon capture - a review of systems and property impacts. Energy Procedia, 142:3741-3746, 2017.

C. H. Twu, D. Bluck, J. R. Cunningham and J. E. Coon. A Cubic Equation of State with a New Alpha Function and a New Mixing Rule. Fluid Phase Equilibria, 69:33-50, 1991.

Z. Ziabakshsh-Ganji and H. Kooi. An Equation of State for thermodynamic equilibrium of gas mixtures and brines to allow simulation of the effects of impurities in subsurface $\mathrm{CO}_{2}$ storage. International Journal of Greenhouse Gas Control, 2012. doi: 10.1016/j.ijggc.2012.07.025

L. E. $\varnothing_{\mathrm{i}}$ and J. Hovland. Simulation of Condensation in Compressed Raw Biogas Using Aspen HYSYS. In Linköping Electronic Conference Proceedings SIMS 59, pages 31-36, 2018. doi: 10.3384/ecp1815331 